\title{
Co-operating with Notational Language: Full-scale Drawing Practices of Traditional Carpentry in Southern China
}

\author{
ADAM BRILLHART \\ China Academy of Art, XJTLU
}

This paper discusses the "representational framework" unique to drawing practices of carpenters in Southern China. The representational system not only integrates their practical experience but also places a reproducible world model in the quasi-linguistic framework operated between tool and component. Fullscale ink markings are discussed as a "notational language" which condensate construction activities around linearization of symbols in full-scale. This hidden structure of traditional form is distinct in its closeness to construction from the dominant forms of instrumental representation in the world since the European Renaissance. The "minimal signifying units" of this particular drawing practice are discussed as a foundation of a special kind of "operational memory" arising through systematic experience. This representational system yields not only an elastic mode of construction in which joint-making generates open meaning, but also a "habitus" of drawing which has undergone regional adaptation.

\section{INTRODUCTION}

This paper negotiates the schism between design and construction in which architectural drawing practice is firmly rooted. In present day, drawing practice as a professional discipline caters to regulatory environments of construction frameworks. On contemporary construction sites, instrumental forms of representation preempt consumption of their geometric and symbolic content without recourse to construction activity. Instrumentality in such a framework effectively creates buildings which are made to look like drawings. In the periphery of the large-scale land transformation and urbanization process resulting from this ethereal, projective mode of drawing, a unique social embodied and elastic mode of production of space, which has arisen through systematic work experience of craftsmen, has nearly completely been lost in China's rural areas. Carpenters working in the tradition of a regional construction system are now faced with standard architectural drawing arriving to the construction site purely as a result of the regulatory process required for approval of the construction. These carpenters believe such drawings are useless in both conceptualizing and realizing the project. The head carpenter facing this situation in Fujian province stated, "the paper cannot be trusted." ${ }^{1}$

This study is intended to discuss how "representational frameworks" which correspond to particular construction systems, shape the collective perception of "place." The practice of traditional carpentry through a specific representational

\author{
KEN YEUNG \\ China Academy of Art, XJTLU
}

model not only integrates the practical experience of the carpenter, but also places a reproducible world model. The unique representational framework of this drawing practice brought with it special functioning tools used on the site of construction according to real scale which determine the component relation in the structure, and produce an elastic mode of construction. The tacit reading of these drawings by craftsmen lies in the vernacular social context, which bears directly on the level of nuance and discursiveness of the drawing practice. Although, the intangible working methods arising through systematic experience and cultivated through guild culture have been almost completely lost, the tools themselves, as communicative records of the notational language, are still intelligible today (to both amateur researchers and students of architecture).

At a deeper level, the direction of operation of the tools discussed is not only for working the wood frame, but also extends to the judgement of buildings and their surrounding environment. In this sense, the signal of operability of the system of tools can be understood as a kind of language structure. That is, tools can be seen as concrete objects that embody regional and cosmological concepts. It also means, that discussion of carpentry tools can not only be confined to the interior of the domain of construction, but also be extended to the broad cultural category of the collective memory of the tectonic process - and more precisely a discussion of what I call "tectonic typology." Through the concept of "tectonic typology" I will explore the symbolic character of tools and their specific operational activities and the possibilities of the construction method, including its potentiality of containing a world-view in drawing. In the cross-cultural conceptual framework, this paper examines the close relation of vernacular construction to the unique drawing practice developed in China's rural areas, attempting to refresh discussion of the concept of "instrumentality" from the perspective of tectonic culture and anthropology.

This paper will outline the tacit knowledge and systematic experience underlying traditional paper-less drawing practice in rural China and attempt to recover the boundless context and openness inherent to its original intention. Further, the hidden representational framework of the Chinese woodworking construction system will be discussed from the concept of operational memory of tools through a structural understanding of the distribution and transformative logic of the "indicative" symbol in the production of space. The 

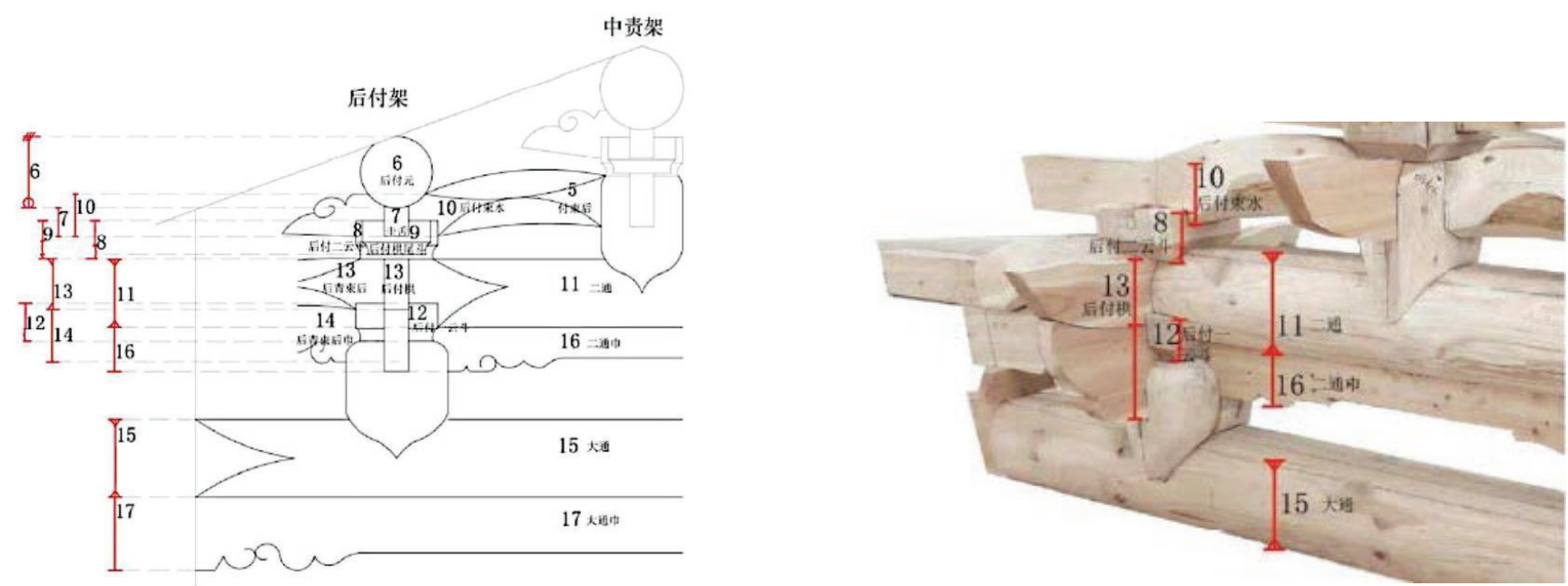

Figure 1. Notational language and corresponding tectonic assembly.(Source: Wu, Xiaoting "A Study on the Gao-Chi Arts for Master Carpenter Tang Shi-meng in the Group Xi-Di of Quanzhou. Fujian" PhD Diss., Huaqiao University, 2016).

method of structural anthropology will be adopted to establish a cross-cultural conceptual framework and a comparative basis of understanding. Through its method of totemic classification, the categorical thinking of distinct construction logics may allow a reexamination of the seemingly professional knowledge of drawing practice and also be understood as an underlying structure of the production of space. ${ }^{2}$

\section{OBSERVATIONS ON REGIONAL NOTATIONAL SYSTEMS OF SOUTHERN CHINA}

In the example of carpentry, a classical text of the Ming Dynasty, Lu Ban Jing, clearly describes the introduction of the environmental representational frame into a panorama of building operation practice. Curiously, Lu Ban Jing is not an operational manual of carpentry. It does not emphasize depiction of the construction steps, mortise and tenon joining methods, or wood structural frames, but rather describes the concrete places and construction ceremonies significant to the existence of the wood structure. Compared with the hierarchical tectonic system depicted in the Yingzao Fashi, another important writing of Chinese woodworking, the Lu Ban Jing, opens a new possibility for the discussion of "tectonic" distinct from the Western concept. That is, the Lu Ban Jing establishes symbolic meaning through specific social rites and expression of bodily labor, not only through aesthetics or a knowledge system.

The drawing practices arising in accord with the framework set out in Lu Ban Jing, through integration of a vernacular representational system, mark the specific concept of measurement in carpentry craftsmanship. Here, people's observation and the structure of architecture are interwoven in a kind of linguistic framework. More interestingly, I found that in the process of constructing the wood structure, the traditional carpenters involved almost no representational drawings. Rather, conventional drawing techniques are deemed unnecessary owing to interpretation of ink markings made directly on the wooden frames. This kind of notation bears a structural relationship to tools and joining operations. In this special construction system, the function of construction tools is not only to process materials, but also to act as a representational system similar to drawing.

In the carpentry system of Zhejiang Province in China, the "single-line drawing" establishes basic structural relationships between the frame and components, without defining the precise form of each component. These kind of drawings can be commonly found around construction sites in rural villages. They are quickly drawn on ready-at-hand materials such as the street or scrap materials (figure 4). The singleline drawing is the first drawing made in the early phase of project, and is important in considering the number of components and their position in the archetypal frame. Each frame is labeled and seen in relation to an undrawn plan, or column network, which is anchored by a central room, where according to ritual described in the Lu Ban Jing, a jade symbolic vessel is hung to transfer spirits. ${ }^{3}$ The tacit understanding of the plan template informs the basis of the frame layout, and is only materialized in labeling or naming frames in relation to the conceptual center. On the single line drawing of the frame, the span and horizontal elevation data may be indicated through textual notation. ${ }^{4}$ The drawing is also used to restrain the often doubly-curved roof, and calculate its corresponding column heights. Through determination of the central axes of each column, it establishes the basic span relationships of the entire framing system as well as criteria for the naming of its component parts.

The single line drawing is taken as a means to establish basic tectonic relationships in a full-scale reduced linear representational space. In this process, the singleline drawing can be understood as a kind of temporary 


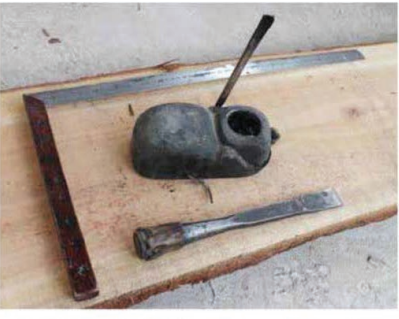

落篙的工具: 竹篦、墨斗、曲尺、刮刀

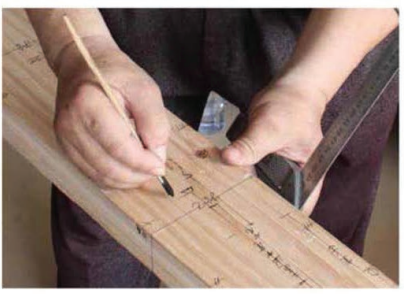

王世猛使用竹篦落篙

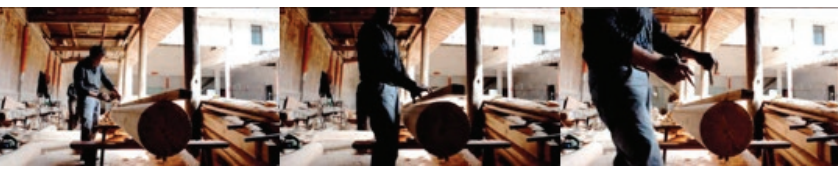

釋名

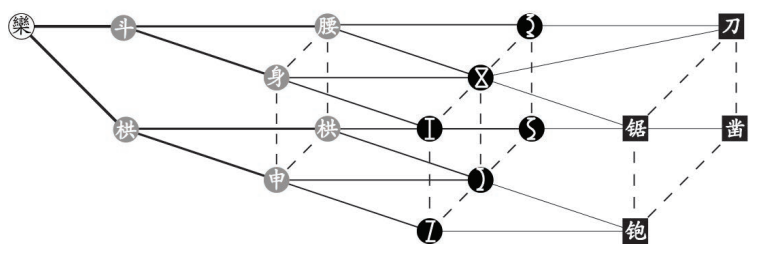

Figure 2. Top, Process of making the fullscale "gaochi" drawing using inkline and ink writing instrument (Source: Wu Xiaoting); middle, Process of transfering notation of the zhanggan onto the column (Source: Lu Chenchen); bottom, Analytic diagram showing relation of concept of component, through its subdivision in linguistic context, and corresponding notation, and tools, required for its realization. (Drawn by author).

elevation drawing which is projected and compressed into one dimension, and transferred to a full-scale wooden stick, called "zhanggan" in Zhejiang Province, and "gaochi" in Fujian Province. Although the functionality of these instruments is essentially the same, the regional differences pertain mostly to their existence as a drawing, particularly in the way in which information is organized and symbolized on the flat faces of the stick, including the manner of expressing minimal signifying units in the notational language. These special drawings may exceed the height of the building in length and be constructed in one day's time. Some carpenters with a high level of tacit understanding may compose the zhanggan or gaochi directly without aid of the single-line drawing. ${ }^{5}$ In this full-scale space, the mutual relationships of frames and vertical differences to one another are rendered visible. During construction, the stick is laid upon columns resting in the workhorse (trestle), while rotation allows the notational system of the measuring instrument to define locations and types of joints in three-dimensions (figure 2).
As observed in Zhejiang province through interviews with traditional carpenters, the use of the ink-line instrument presupposes a notational language on the vertical coordinate system of the body of each column. The method of representing a string of information along these axes, is assisted and realized through use of the zhanggan instrument. In these drawings, the basic module, called "doukou" in Chinese, establishes a gradation which is used as a basic unit of measurement in the full-scale representational space to assure precise correspondence of joint locations relative to each column. This system of differentiating simple scaled lines can be understood as a mnemonic device which represents tectonic components and further defines an axis of selection, where combination and composition belongs to the primary level of articulation. These linguistic elements of the notational language which bear structural relationships to tools and joining methods may be understood as a foundation for operational memory ${ }^{6}$ (figure 3).

The "zhanggan" instrument plays the same kind of role as scaled drawing and model making which communicate design intention and refer to the proportion and mutual relationship of the tectonic components within the structural system. However, compared to descriptive geometry, the zhanggan assumes a more concrete indexical relationship among structural components and tools. The complexity of symbols represented in the zhanggan exceed the general understanding of conventional drawing, and enter the domain of direct operation on material. That the drawing is able to reach this level, may be explained both through the systematic work experience of the carpenter and legibility maintained in the reduction to symbol. The categorical thinking which extends the drawing practice to real operational activity, correlates each kind of structural component with a linear symbol whose extremities and subdivisions indicate heights and whose mutual overlap in the coordinate system tacitly indicate depth of joints and method of connecting one component to another.

As a form of drawing, the "gaochi" instrument may be understood as an apriori carrier of symbolic meaning which contains the indexical symbol in Charles Peirce's semiology. ${ }^{7}$ Although a primary function of the "gaochi" drawing is to classify structural components and index corresponding operations, the symbols composed on its length open operational space to thinking of particularities of the tectonic through minimal signifying units. The condition of the wood material by which symbol is made in the drawing practice of traditional carpenters in Southern China not only allows operability and physical relocation of the representational system around the construction site, but also stands as an as-built record of the design whose corporeal dimension also lends a didactic educational awareness to the human scale and categorical thinking inherent to the tectonic system. 

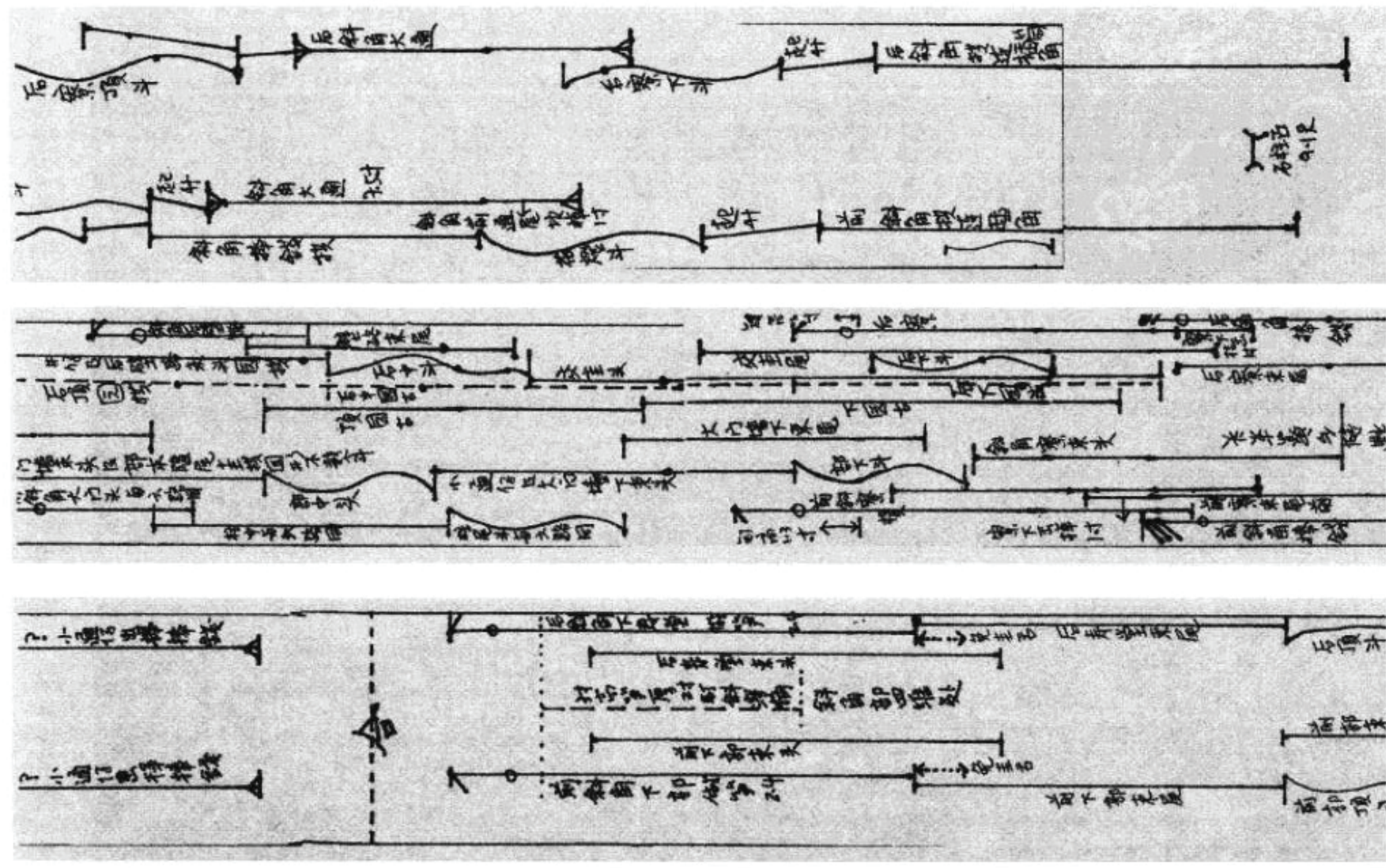

Figure 3. Composite photograph showing the notational language of the full-scale "gaochi" drawing. (Source: Zhang Yuyu).

It was observed in Fujian Province, that the gaochi drawing described does not disappear after construction like most drawings. The end it serves, after all, is not confined to a particular phase of construction. Rather, traditionally it was stored in the roof rafters of the house to assist in future repairs. ${ }^{8}$ As artifice, the indexical quality of the drawing is comprehensible in everyday village life, even to amateurs dwelling in a place where tools are more ubiquitous. That the gaochi drawing was kept alongside the building after its construction, presents an interesting point of reflection, even to common villagers. The "minimal signifying units" may be understood visually through a simple full-scale operation which correlates the actual wood structure and tectonic detailing with the notational language on the "stick" (figure 1).

Such a structural comparative basis between notational language and building, has led me to return to the concept of "minimal signifying unit" from which symbolic analysis originates. If detail is the minimum unit of signification in the architectural production of meanings, the joint may be understood as containing ideal values of the frame, which present adaptability to regional aspects. ${ }^{9}$ Here, detail allows a finetuning to material and cultural thinking, and more specifically, expression of joining through detail indicates operability in a process of generating open meaning in regional constructional systems. Further, incremental regional development of the drawing system within tacit constraints of the representational framework has produced typological variation through nuanced operation of the drawing practice. Accordingly, the symbols on this type of drawing never completely override elementary knowledge and aesthetic perception and for this reason the drawing practice may be interpretted as an open work. ${ }^{10}$

\section{REFLECTIONS ON REGIONAL NOTATIONAL SYSTEMS OF SOUTHERN CHINA}

Through field work and research in rural China, a certain degree of operability of the tectonic system was observed. The unique temporality characteristic of these structures, in the case of performing repairs and constructing additions to houses, reconnect the drawing process to modification and begin to reveal the endless re-interpretation and semiosis of tectonic activity in the social context. As such, the vernacular representational framework observed in Chinese villages may be understood as a kind of "immune system" against the absolute authoritative and technocratic systems, which set a professional and legally binding constructional system for architecture. 

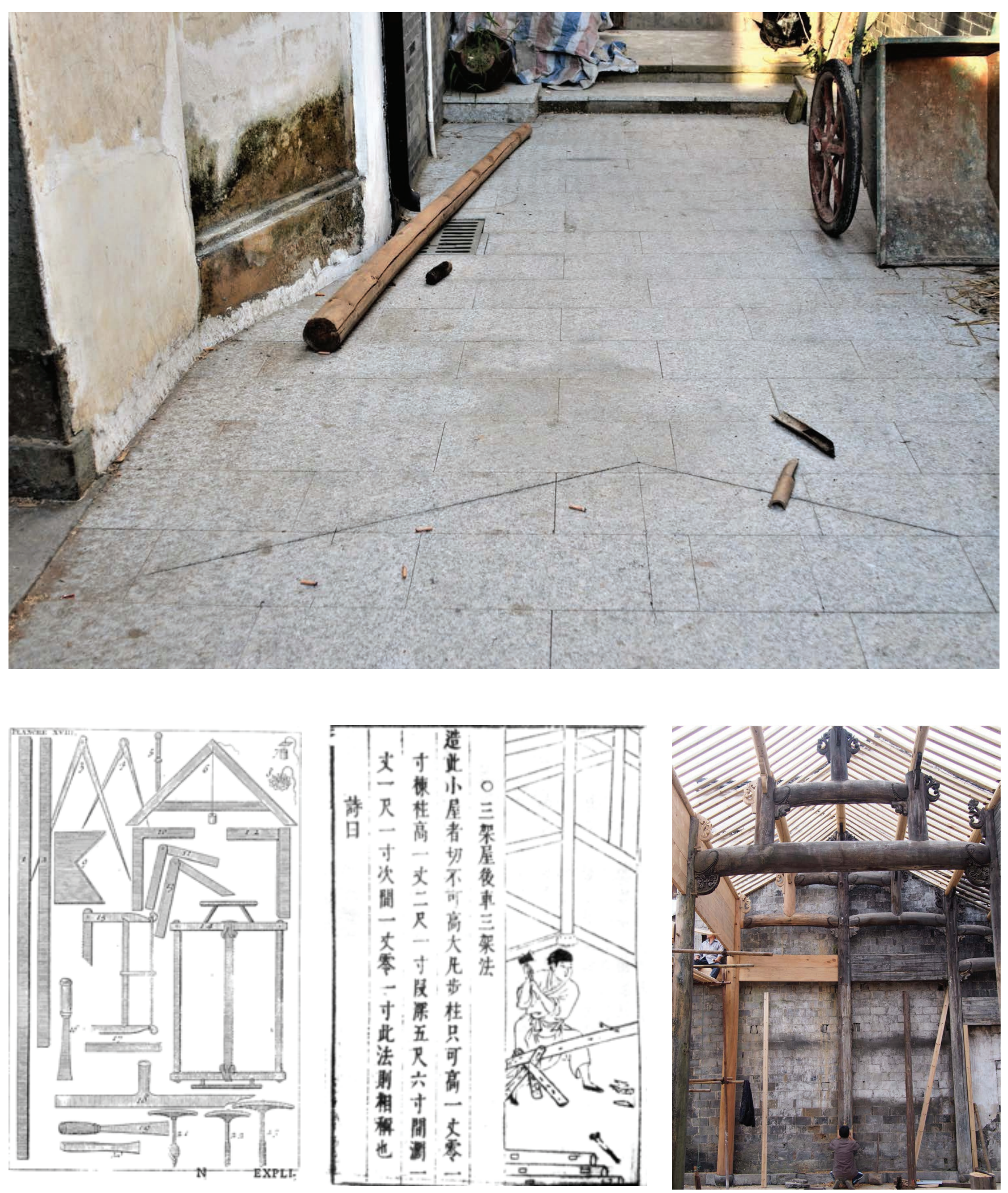

Figure 4. Top, Photograph of "single-line drawing" constructed on street, in Longmen Village, Zhejiang Province; bottom right, "Hundred Step Hall" under repair, Longmen Village, Zhejiang Province, 2015 (Photographs by Author). Figure 5. Bottom left, Plate from Andre Felibien (Source: Getty Research Institute, 90); bottom middle, Excerpt from Ming Dynasty Carpentry Manual, Lu Ban Jing (Source: Klaas Ruitenbeek). 
Many modern architects and theorists have tried to explore the problem of "notational system" through renewing discussion of Renaissance architectural theory, to then reinterpret the problem of continuity of cultural tradition. Leon Battisti Alberti in the end of Book 6 of De Re Aedificatoria describes a direct working method of transferring the "lineaments" onto material by constructing the profile line (finitor) of columns through proportional ratios derived from the diameter of the column. Starting with the central axis of a column, a full-scale wall-drawing is used to fashion a full-scale template which is then carried to the quarry. ${ }^{11}$ In this mathematically controlled construction logic, buildings effectively are made to look like drawings by equal imposition of form onto both the conceptual image of the building and concrete material operations. As opposed to the absolute control of Alberti's method, the logic in traditional carpentry is predicated on a notion that development of the drawing is contemporaneous with construction activity, rather than explicitly preceding it. ${ }^{12}$ Rather than outlining or specifically referring to its final cause in formal terms, the regional representational system discloses intention and potentiality by interrelating parts through joint-making.

The ideal of measurement in this system is not to define everything. Although distinct from Alberti and modern instrumental representation which followed, the conception of measurement in traditional Chinese carpentry seems to resonate with a contemporary of Alberti, 15th Century German philosopher, Nicholas Cusanus. The title of his book "Learning Ignorance" not only refers to this key concept of relativism, but also to the distinction between the "sensible " and "intelligible." Cusanus' theory pays particular attention to the concept of "measurement" by proposing that all "knowledge" can be defined by measurement (similar to measurability in modern science), and that "proportion" is the medium of knowledge (as a measure of the relationship between one measure and another), which includes measurements. ${ }^{13}$ Accordingly, the analogical structure of proportion in the representational system of Chinese carpentry is left partially to the mind and is only partially constrained through positing of distances between symbol. Likewise, Lu Ban Jing describes how intelligible meaning is controlled through connotative measurement of spans and vertical dimensions of components. The cultural meaning which was attributed to measurement reflects an ideological position of the archetypal frame. Its legibility in the reduced representational space of drawing, was presumably a ground for discussion between craftsmen and scholars, in which the question of how to control became an art itself. ${ }^{14}$

In a cross-cultural examination of the representational frameworks underlying traditional form, a clear distinction may be made between the "boundless" context of Chinese representation of tools and the chamber-like representation dominant in French building treatises during the pre-Enlightenment period. Symbolic representations and descriptions of tool operation and environment in Lu Ban Jing clearly emphasizes the human body and its postures. In a Heideggerian sense, the environing world seems ready in a topographic context, whereas in French Treatises from the 17th century, a list-like representation of symbolic tools appears in an abstract and world-less context (figure 5). Thus emphasis of a taxonomy rather than an operating environment characterize distinct conceptualizations of the semiological spaces of workshops. From the perspective of knowledge archaeology, the discussion has gradually shifted from the study of "tools" to the study of modes of representation which underscore the cultural attitude latent in distinct types of drawing practice.

In the European context, a discourse had begun to be developed which plainly challenged the modern paradigm of drawing practice. Adolf Loos attempted to renew discussion of directness in the production of space, criticizing standard architectural representational methods and opposing drawing practices using strings of dimensions. He said, "If I want a wood panelling or wainscot to be of a certain height, I stand there, hold my hand at a certain height, and the carpenter makes his pencil mark. Then I step back and look at it from one point and from another, visualizing the finished result with all my powers. This is the only human way to decide on the height of a wainscot, or the width of a window." 15 Loos is criticizing the abstract, projective mode of drawing, for the reason that it has lost the foresight of tactility with the body. Loos raised a sharp point of view correlating the "graphic nonsense" of conventional drawing with the weakening of the craftsman's sensibility. Loos' thinking opposed the entire mode of production and the conceptual framework of the architect furnishing builders with drawings.

The underlying basis of productive legibility in modern instrumental representation was discussed at great length by American philosopher, Nelson Goodman. In the chapter entitled "Reduction and Construction" from his book "Ways of the World-Making," Goodman theorizes building as an art of performing a kind of symbolic understanding through drawing which allows others to perform construction operations. In this context, Goodman defines theoretical requirements of "notational language"16 and discusses the potential of its interpretation in relation to other arts. The categories of intensional and extensional agreement function to reveal a mixed degree of co-dependence between instrumental representation and notational systems, which also reflects on cultural concepts of precision, a thread which has also been developed in architectural theory and anthropological studies.

In the past ten years, many researchers of architectural history have made a certain level of contribution to the "notational system" of the Chinese carpentry construction system. Among them, most importantly, Chinese scholar Zhang Yuyu's detailed study of the "zhanggan" representational system. Such research 
emphasizes the practical operation of the notational system in traditional carpentry, and represent it as a kind of "taxonomy diagram." These analytical diagrams bring a more complete framework of systematic knowledge of the carpenter's operating system, highlighting the complex relationship between the notational system, and corresponding methods of shaping and connecting concrete components.

Italian neo-Marxist Franco Berardi goes further to resolve understanding of the notational system (instrumental operational system) as a "transformation of a logical concept." He describes the "linguistic tendency" which reduces social thinking and imagination by one-dimensional logic to its functional form. ${ }^{17}$ The problem with this kind of discussion is that the "notational language" in Chinese carpentry system, will degenerate into a kind of abstract code detached from the social and cultural context, as well as the movement and intention of operation in its moment of arising. In spite of this, it is particularly important to refine the concept of notational language in order for it to become a basis for design thinking to reflect on the trans-cultural context of drawing practices which underlay "tectonic typologies."

As French anthropologist Andre Leroi Gourhan noted, the problem of operational memory is dominated by that of language, ${ }^{18}$ meaning that it is structured according to how our language works grammatically. From the authors' understanding, if this principle is applied to construction of the archetypal frame, the inclusion of named tectonic parts as a mental template, would present a greater ability to be refined in terms of purpose or articulated in terms of expression. From this basis, the quasi-linguistic subdivision of the frame into categories of parts may be understood. Owing to the tacit noumenal dimension of the notational language, parts are spatially disclosed as empty containers. That such learned intellect and imagination could be expressed through notation in the zhanggan drawing, presents an example par excellence of commensurability in practice. This kind of becoming works upon material (not with material) and in effect the building comes through drawing, rather than being made to look like drawing.

\section{CONCLUSION}

In the Chinese carpentry construction system, craftsmen believe architectural drawings are unnecessary. From their systematic work experience, carpenters believe that there exists a more direct relationship between wood working tools and construction of the frame. This concept is reinforced by the hierarchical stratification of building types practiced since the Ming dynasty. Once placed in such symbolic structure of the imperial sovereignty, the indexicality of the representational framework they practiced in carpentry is apparent and even necessary.

However, this paper tries to argue, that the tacitness in which building operation activity became "indexed" through carpentry's unique representational framework, effectively replaced the need for representational drawing, and accordingly that the "notational language" drawn directly on the wood material of parts of the frame represents an operational memory of construction. Through methodology adopted by Claude Levi-Strauss' structural anthropology, structural concepts observed through the minute differentiation in its parts may project the ideological image of the whole. In this sense, the tectonics of the archetypal frame and categorical relationships of joints may be explored through analysis of notation in the zhanggan instrument.

While such tacit practice of 'drawing' slowly came to light, a dilemma remains: although the research has its own value in revealing carpentry practice in full capacity, nowadays the rituals once practiced which were necessary to keep such an indexical system semiologically charged, may hardly be found. The carpenters' practice has peered off from these cultural layers over time, where the marked physical joints of the notational language allowed one to enter the codified operational memory. Through a cross-territorial comparison, the diversity in local modification of the components helps to reflect the room which was left for cultural diversity in the fixated codified system. In this sense, the operations manifest in regional modifications allow entry into a new domain, in which the thing signified through "minimal signified unit," be it a joint or a component, could be made to open new meanings within the typological index.

For example, between the differentiated ends of a particular linear symbol on the gaochi, one may observe a differentiated line or curve, which relate it to the type of thing it is (in the structural system). This level of articulation bears on its intelligible meaning manifest primarily in oral communication. On a deeper level, however, when one observes what was realized immediately in the hands of the carpenter, a level of articulation which is unexpressed in the notational language can be found, particularly in parts of the tectonic whose structural role is more ambiguous. These parts are a touchstone for understanding aspirations of building in the representational framework discussed.

Understood in this context, the 'paperless drawing' in the case of Chinese carpentry suggests a very different ideal compared to the practice of absolute control from the Renaissance. The aim of producing a continuous endless diversity under the same underlying rule, to a certain extent, is also apparent in the traditional Chinese mountainous painting. Under such ideal, the emphasis of the stroke to mnemonically recall mountain and water, is drawn and codified as a notational language to carry meanings similar to the carpentry practice. This shines light on a new possibility in understanding typologies in modern architecture theory. Hence, the term 'tectonic types' suggests that it is the tectonics of the parts and components which carry its typological cultural continuity, rather than its outer appearance, silhouette, and materiality. 


\section{ENDNOTES}

1 Yuyu Zhang, Studies on the Craftsmanship of Traditional Chinese Carpentry in Fujian Region (Nanjing, China: Dongnan Daxue, 2010).

2 Claude Levi-Strauss, The Savage Mind (Chicago: University of Chicago Press, 1966).

3 Klaas Ruitenbeek, The Lu Ban Jing: A Fifteenth-Century Chinese Carpenter's Manual (Leiden, Netherlands: Brill, 1933).

4 Chenchen Lu, "Carpentry in Southern China," YouTube video, October 3, 2014. https://www.youtu.be/6HFZEwn-nKY.

5 Zhang, Studies on the Craftsmanship of Traditional Chinese Carpentry in Fujian Region.

6 Andre-Leroi Gourhan, Gesture and Speech (Cambridge, MA: The MIT Press, 1964).

7 Charles S. Peirce, "Logic as Semiotic, The Theory of Signs," in Philosophical Writings of Peirce (New York: Dover Publications, 1902).

8 Zhang, Studies on the Craftsmanship of Traditional Chinese Carpentry in Fujian Region.

9 Marco Frascari, "The Tell-The-Tale Detail" in Theorizing A New Agenda for Architecture (Princeton, NJ: Princeton Architectural Press, 1996).

10 Umberto Eco, The Open Work, trans., Ana Cancogni (Cambridge, MA: Harvard University Press, 1989).

11 Leon Battista Alberti, On the Art of Building in Ten Books, trans., Joseph Rykwert, Niel Leach, and Robert Tavernor (Cambridge, MA: The MIT Press, 1991).

12 Tim Ingold, Being Alive: Essays on Movement, Knowledge and Description (London: Routledge, 2011). The distinction between hylo-noetic (Greek:nous for mind) and hylo-morphic (Greek: hyle-meaning wood and morph meaning form) making methods was discussed at length in the work of anthropologist Tim Ingold.

13 Ernst Cassirer, The Individual and the Cosmos in Renaissance Philosophy (New York: Dover Publications, 2011).

14 Ruitenbeek, The Lu Ban Jing: A Fifteenth-Century Chinese Carpenter's Manual.

15 Francesca Hughes, The Architecture of Error: Matter, Measure, and the Misadventures of Precision (Cambridge, MA: The MIT Press, 2014).

16 Nelson Goodman, Languages of Art: An Approach to the Theory of Symbols (Kansas City: Bobs-Merrill Company, 1968).

17 Franco Berardi and Giuseppina Mecchia, "Technology and Knowledge in a Universe of Indetermination," Substance 36, no. 1 (2007): 56.

18 Gourhan, Gesture and Speech. 